\title{
Creativity and psychoactive substance use: A systematic review
}

\author{
Fruzsina Iszáj $^{1}$, Mark D. Griffiths ${ }^{2}$, Zsolt Demetrovics ${ }^{1}$ \\ ${ }^{1}$ Department of Clinical Psychology and Addiction, Institute of Psychology, Eötvös Loránd \\ University, Budapest, Hungary \\ ${ }^{3}$ Nottingham Trent University, Psychology Department, Nottingham, United Kingdom
}

\section{*Corresponding Author:}

Zsolt Demetrovics

Institute of Psychology, Eötvös Loránd University

Izabella utca 46, Budapest, 1064, Hungary

Phone: +36 30 9761097; Fax:+3614612697

Email address:demetrovics@t-online.hu

\section{Acknowledgement}

This study was supported by the Hungarian National Research, Development and Innovation Office (Grant numbers: K111938).

\section{Conflict of interest}

The authors declare that they do not have any interests that could constitute a real, potential or apparent conflict of interest with respect to their involvement in the publication. The authors also declare that they do not have any financial or other relations (e.g. directorship, consultancy or speaker fee) with companies, trade associations, unions or groups (including civic associations and public interest groups) that may gain or lose financially from the results or conclusions in the study. Sources of funding are acknowledged. 


\title{
Creativity and psychoactive substance use: A systematic review
}

\begin{abstract}
The role of psychoactive substance use in the research of artistic creation and creativity is a long-standing topic. Ever since the discovery of LSD, researchers have examined the relationship between the effects of chemical substances and the artistic creative process. The goal of the present study was to systematically review all published empirical publications and case reports in refereed journals that focused on the relationship between psychoactive substances and creativity/creative artistic process. A total of 19 studies were identified that met the inclusion and exclusion criteria. Results were difficult to summarize because of the different study questions asked, the diverse methods used, the different samples applied, and the various substances examined. The general results suggest that there is an association between creativity and substance use. However, the studies were unable to show that substance use directly contributed to the growth of creativity or facilitated creative artistic process. It is concluded that specific skills may be subject to change as a consequence of substance use, and consequently may have an effect on the style of creation.
\end{abstract}

Key words: artistic process; creativity; psychoactive substance use; drugs; empirical research; systematic review 


\section{Creativity and psychoactive substance use: A systematic review}

\section{INTRODUCTION}

From a psychoanalytic perspective, Kris (1962) asserted that creative work can be interpreted as a process containing two phases. The first phase is "inspirational" where the artist is passively present in the process. This phase shows many similarities with regressive processes in terms of id impulses and drives that are in touch with the ego, which is difficult to achieve under normal circumstances. This phase gives the content of the artwork dominated by unconscious and preconscious functioning. In the second "elaboration" phase, such ego functions are used as the analysis of reality and logic. This phase requires concentration, purposive planning, and problem solving. It is argued that what the artist passively received in the first phase is reconstructed in the second phase and made understandable to others. The two phases can either follow each other linearly, or they can alternate or combine. From another viewpoint, inspiration can be defined with three main characteristics by Thrash and Elliot (2003). These include evocation, referring to that inspiration evolves by a stimulus or stimuli rather than by the artist's volition. Additionally, transcendence is necessary - ordinary views might transcend into fresh, interesting ideas. If the artist feels the urge of sharing the new vision, this is called approach motivation. If these three elements are present, the inspirational state comes to existence. Moreover, Trash et al. (2010) assert that inspiration often results in actualization that is a similar notion to Kris's elaboration phase. However, Oleynick et al. (2014) use the term 'inspiration' not as the source of creative thoughts, but rather as the transmission of creative ideas. So, it is conceptualized as a state of motivation.

Jung (1971) considers the artistic creative process to be an autonomous action that lives in the person independently from consciousness. Depending on the energetic processes, it can appear either as a disturbing element of conscious processes or as an entity above the 
ego that is capable of dominating the ego. In this sense, artistic creation develops unconsciously and is able to break into consciousness if it reaches the edge of it. The association that breaks this way into consciousness can be interpreted not as assimilation, but as perception that cannot be consciously controlled or intentionally reproduced. That is why the consequences seem to be autonomous, and whether they appear as a form of art or simply disappear depends only on the inner tendencies. According to Jung, the collective unconscious is also a source of art. In the normal state of consciousness, the unconscious cannot communicate with consciousness, although it could be fulfilled more easily with the artists' higher sensitivity. Here, the artist appears as a collective person and goes beyond their personal experiences and feelings, experiencing a certain amount of relief. Jung introduces the term visionary to explain the mood of artistic creation - such materials or experiences serve as the basis of works that are unknown and strange to the artist.

The line between healthy and pathological artistic creation is very narrow. Ehrenzweig (1970) thinks that in both cases, material rises from unconsciousness. The difference lies in that in case of mental illnesses, unconscious contents disturb the process of conscious thinking, and that chaos overwhelms the individual's intellect. On the contrary, during the creative process, the individual is able to control the material emerging from unconsciousness and conscious thinking. However, artists' higher sensitivity is essential for fulfilling their work. Oleynick et al. (2014) and Thrash et al. (2010) agree that although inspiration is necessary for creation, the artist's effort is very important and that self-regulation is required to fulfill the artwork.

The humanistic approach stresses the protective potential of creativity. Rogers (1961) is of the opinion that the primary goal of creation is the individual's self-fulfilling nature. Creativity is essential for living a full, healthy life. Maslow (2011) also discusses the relationship between self-actualization and creativity. "Self-actualizing (SA) creativeness" is 
a kind of creativity that appears in every field of life (such as humor). Self-actualizing individuals do everything in a creative way which can be connected to a special kind of perception. They lack the fear of unknown both inside and outside, and more self-acceptance is specific. In addition, primary and secondary creativity are distinguished depending upon which (primary or secondary) processes are used in creation. If both are used, integrative creativity emerges. Forgeard and Elstein (2014) share these views. In their opinion, creative thinking might help to improve psychological flexibility and therefore better coping strategies can be evolved. Furthermore, it might facilitate adaptive future thinking. However, it is not yet clear how creative thinking affects psychological flexibility. For example, does creative thinking influence flexibility more than other thinking styles?

When working with both conscious and unconscious material, the artist's inner struggle is characterized by emotional fluctuations that can be difficult to handle (Iszáj \& Demetrovics, 2011). The inspiration phase has been described as a regressive, ecstatic state (Kris, 1939). Part of the unconscious content might be converted and externalized in words, pictures, and/or daydreams that have appropriate emotional charge (Kris, 1962). To handle these extreme emotional states, artists might use psychoactive substances. Possible reasons for artists' substance use might be the achievement of experiences of depersonalization and derealization. These phenomena are also observable in psychotic individuals. Substance users seek mental states that can help loosen personality and reality experiences and achieve special, altered perceptual states. A further reason can be that artists wish to provoke unusual modes of cognition (Knafo, 2008). Dobkin de Rios and Janiger (2003) state that artists tend to use substances to alter their state of consciousness that might facilitate creativity. From among several examples, Aldous Huxley might be the most well known literary figure whose book The Doors of Perception (1954) concerned his first mescaline experience. The paintings of the Dutch painter Henri Michaux were also inspired by psychedelics. The writer Robert 
Louis Stevenson was under the influence of cocaine while writing the 1886 book Strange Case of Dr. Jekyll and Mr. Hyde (Knafo, 2008). In a study analyzing the life and artistic work of Edgar Allan Poe and Samuel Taylor Coleridge, the artistic creative process was suggested as an enhanced risk factor regarding psychoactive substance use. The use of these substances might have a role in both phases of the creative process. Artists might use substances to stimulate their experiences and to reach regressive states. On the other hand, specific psychoactive substances might help in reorganization and the alleviation of the exaggerated tensions (Iszáj \& Demetrovics, 2011). The idea of Khantzian's (2003) self-medication hypothesis may be applicable here. This means that users try to regulate their emotions, behavior and interpersonal relationships via their substance use. Given these observations, the goal of our present study was to review the current knowledge available on the relationship between creativity/artistic creative process and the use of psychoactive substances.

\section{METHODS}

\section{Search strategy}

All studies were considered for inclusion that provided empirical data on the relationship between psychoactive substance use and creativity/artistic creative process and had been published in English in peer-reviewed journals or scientific books. For the review of the literature the following databases were searched: PsycINFO, MEDLINE, PubMed, Science Direct, Web of Science, and EBSCO. The electronic search was executed for two groups of keyword combinations. For substance use, the following keywords were used: drug*, psychoactive substance use, psychedel*, psychotrop*, hallucinogen*, LSD, magic mushroom, mescaline, peyote, and psilocybin, while for creativity, the following keywords were used: creativ* $^{*}$ and $a r t^{*}$. The electronic search was supplemented by a manual search. This meant that the reference list of each study identified in the database search was read, and further 
studies that had not shown up in the electronic search were added to the studies for further review.

\section{Exclusions}

During the electronic search, as a result of the combination of the two keyword clusters, 327 studies were identified and the overview of the references resulted in one further examination. In the case of 179 papers, the keyword $a r t^{*}$ referred to other meanings than artistic procedure (e.g. artery, arthritis, artificial); these papers were excluded from analysis. Furthermore, 97 papers dealt with other aspects than the focus of our study (e.g., art therapy). In the following step, book reviews $(\mathrm{n}=2)$, one doctoral dissertation, and the non-English language studies $(n=6)$ were also excluded. A further 22 studies were excluded because they did not contain any original empirical results and only reviewed the literature. Studies that dealt with the effects of alcohol use were also excluded $(n=2)$. Following this filtering process, 19 studies remained for further analysis (14 empirical studies and five case studies).

\section{RESULTS}

\section{Publication date and geographical location of the studies}

Five of the 19 studies (four empirical papers and two case reports) were published during the 1960s and 1970s. However, following the peak of psychedelia, only three papers (all of them empirical) were published in the following 20 years. Since 2003, a further 10 studies were published (seven empirical papers and three case studies). The majority of the studies $(58 \%)$ were published in the USA. This dominance is especially true for the early studies in which six of the seven empirical papers and both case studies that were published before mid-1990s were written by US researchers. However, over the past 14 years, this tendency has changed (see Table 1). The seven empirical papers published post-2000 were 
shared between six different countries (USA, UK, Italy, Wales, Hungary, Austria), and the three case studies came from three countries (USA, UK, Germany).

- - - Table 1 - - -

\section{Types of the substances}

Seven empirical papers and two case studies dealt with the relationship between various psychoactive substances and artistic creation/creativity. Among the studies that examined a specific substance, six (three empirical papers and three case studies) focused on the effects of either LSD or psilocybin. One empirical study focused on cannabis, and one concerned ayahuasca.

\section{Methods of the studies}

\section{Samples}

With the exception of one study (Edwards, 1993) where the sample focused on adolescents, all the studies comprised adults. More non-clinical samples (15 studies, including case studies) were found than clinical ones (four studies). Of the clinical studies, Edwards' (1993) study was conducted in a private psychiatric hospital among chemically dependent adolescents. In Korngold's (1963) study, psychiatric patients were compared to a volunteer control group. Four groups (clinical and non-clinical) were the subject of Fink et al.'s (2012) study; actors, alcohol and polydrug dependent patients, and a university control group. Finally, Richards and Berendes' (1977) case study focused on a creative writer with depressive symptoms.

\section{Methodological approaches}


Three different methodological approaches were identified. Among the empirical studies, seven used questionnaires. The most frequently used assessment measure was the Torrance Test of Creative Thinking (TTCT) (Torrance, 1974) in three cases (Edwards, 1993; Frecska et al., 2012; Fink et al., 2012). Additionally, Fink et al. (2012) studied verbal creativity with the use of the Verbal Imagination subscale of the German Berliner Intelligenz Struktur Test (Jäger, Süß \& Beauducel, 1997). The remaining four studies used a range of diverse tests. In Steffenhagen et al.'s (1976) study, the Art Scale (Barron \& Welsh, 1987), the Study of Values (Allport, Vernon \& Lindzey, 1931), and the Fromm-Maccoby 'Life Orientation Test' (Scheier \& Carver, 1985) were used. Three measures of creativity were used in Jones et al.'s study (2009); the Consequences Behavioral Test of Creativity (Christensen, Memfield, \& Guilford, 1958), self-assessed performance from the Consequences Test, and Gough's Creative Adjective Checklist (Gough, 1979). In Harman et al.'s study (1966), creativity was assessed using the Purdue Creativity Test (Lawshe \& Harris, 1960), the Object Visualization Test (Miller, 1955) and the Embedded Figures Test (Witkin, 1950). The modified version of Adjective Check List was used in Lowe's study (1995). The effect of cannabis on creativity in the study by Schäfer et al. (2012) was assessed using the Remote Association Test (Mednick \& Mednick, 1967).

Analyzing artworks was another method employed in some studies. In Dobkin de Rios and Janiger's (2003) study, the participants' drawings were analyzed in normal and altered conscious states. In Landon and Fischer's (1970) study, writing by two participants created during psilocybin intoxication were compared to Walt Whitman's writings. In Fischer and Scheib's (1970) study, both handwriting and drawing were analyzed. Finally, Lowe (1995) analyzed reports from the Mass-Observation Archive to assess if there was any association between creativity and psychoactive substance use. 
The participants' normal and altered states of consciousness caused by LSD were compared in the studies by Dobkin de Rios and Janiger (2003) and Korngold (1963). Landon and Fischer (1970), and Fischer and Scheib (1970) examined the effects of psilocybin. In Harman et al.'s (1966) study, mescaline was used. In another case (Frecska et al., 2012), ayahuasca was used, while in Schafer et al.'s study (2012), the altered state was facilitated by cannabis use.

\section{Results of the empirical studies}

According to the types of psychoactive substance effect on creativity, three groups were identified. These were studies that examined the effect of psychedelic substances $(n=5)$, the effect of cannabis $(n=1)$, and those that did not make a distinction between substances used because of the diverse substances used by participants in the samples $(n=7)$. In one study, the substances studied were not explicitly identified.

\section{Psychedelic substances}

Harman et al. (1966) examined the effects of psychedelic substances on creative problem solving ability among 27 male participants. Three criteria were used in the recruitment process. The participants had to be (i) in a profession where there was a strong need for problem solving (ii) psychologically healthy, and (iii) motivated to discover. Three creativity tests were administered prior to and during the use of mescaline or LSD (i.e., Purdue Creativity Test; Miller Object Visualization Test; Witkin Embedded Figures Test). The results suggested that the substances enhanced creative problem solving, especially during ingestion. Although the study only included a two-week follow-up, participants reported significant changes in their problem solving mode. Higher levels of creative achievement remained at least a few weeks after the session. 
Two studies examined the effects of LSD on creativity. Janiger's large human subject LSD experiment carried out in the 1960s $(\mathrm{N}=930)$ studied several aspects of LSD use (Dobkin de Rios \& Janiger, 2003). One part of the study investigated the effects of LSD on creativity upon 20 participants (all professional artists). As an experimental task, the professional artists had to draw a Deer Kachina doll prior to, and at the peak of LSD ingestion. From the 250 drawings and paintings (created over a period of seven years), a total of 65 items by 20 artists were selected for further analysis. These items were formally evaluated by a professor of art history who used eight judging categories (e.g., composition, color, value characteristics, etc.). The most important changes were found in dominant style, color, linear, and textural characteristics. Janiger reported that alteration and fragmentation were the most changed elements, and that artists tended to focus on specific parts rather than the whole work. Colors became more intense and lines altered to become curvilinear. Regarding the altering of perceptions, Janiger's participants reported that a greater freedom from 'prescribed mental sets' was available, and that there were far more associations, images, and/or synesthesia. The follow-up showed that artists evaluated their works created under the influence of LSD to be aesthetically superior. In the other LSD study, Korngold (1963) examined two specific aspects (i.e., esthetic experience and creative originality). The study was written from a qualitative point of view, and quotations were presented about the LSD experience in relation to the two aforementioned aspects. The study has a number of methodological problems (including no mention of the number of participants).

One study examining the effect of psilocybin on creativity was published in the early 1970s (i.e., Fischer \& Scheib, 1971). The study comprised 21 college volunteers that took psilocybin in a controlled setting. Their drawings and writings were analyzed before, during, and after the drug-induced state. The authors reported that psilocybin aroused the creative performance. However, the authors also noted that the drug's effect only strengthened 
characteristics that were already present in the individual, so the results were highly dependent on individual differences. Finally, a study by Frecska et al. (2012) examined the effect of ayahuasca on creativity. The study comprised 40 participants (17 males) who participated in series of tasks using ayahuasca. Their originality scores assessed using the Torrance Test of Creative Thinking (TTCT) was found to be significantly higher compared with the control group that comprised university students ( $\mathrm{n}=21 ; 10$ males).

\section{Cannabis}

The effects of cannabis on divergent thinking were studied by Schäfer et al. (2012). In their study, 160 cannabis users were tested on two separate days (one intoxicated and one non-intoxicated). From the extremes of the sample, two groups were formed - a low creative group $(n=47)$ and a high creative group $(n=43)$. The results showed that the performance of the high creative group did not change on either of the two days. However, in the verbal fluency task, the low creative group improved significantly on the intoxicated day, suggesting an improvement in divergent thinking. On the non-intoxicated day, the high creative group scored significantly higher compared with those having lower creativity. The authors concluded that cannabis might enhance some aspects of creativity.

\section{Various psychoactive substances}

Seven studies examined the relationship between various substances and the artistic creative process. Lowe (1995) and Plucker et al. (2009) conducted studies using normal samples. In Lowe's study (1995), 619 average persons' (459 females and 160 males) texts were analyzed by eight independent raters. A low, but significantly positive correlation was found between creativity and substance use. Lowe concluded that a causal relationship between creativity and substance use could not be determined and suggested 'risk-taking' as a 
common factor. Plucker et al. (2009) studied creative personality characteristics and the use of tobacco, alcohol and cannabis among 431 university students. The authors were interested in the question of whether the creative personality is associated with psychoactive substance use or not. No significant correlations were found between personality characteristics and the use of psychoactive substances.

Psychoactive substance users were examined by Edwards (1993) and by Jones et al (2009). In Edwards' (1993) study, the sample comprised 15 substance abusing hospitalized adolescents and 15 non-substance abusing adolescents. Flexibility and overall creativity were assessed with the Figural A Form of the TTCT administered together with an IQ test. The hypothesis that the participants in the substance-user group would have significantly lower scores in both flexibility and overall creativity scales of the TTCT was supported. Jones et al. (2009) examined the effects of ecstasy and cannabis use on creativity. The study comprised three groups (15 abstinent cannabis users; 15 abstinent ecstasy/MDMA users; 15 nonsubstance controls). The results showed that chronic cannabis users gave significantly more 'rare-creative' responses than the control group, although no significant difference was found among the ecstasy/MDMA users.

Preti and Vellante's (2007) study compared the substance use of 80 artists with a control group $(\mathrm{n}=80)$. The artists (i.e., the creative participants) scored higher on the Delusions Inventory (PDI) designed for measuring psychosis proneness (Peters et al., 1999), and they used more of any kinds of psychoactive substance. The authors suggested that artists' enhanced substance use might partly be responsible for the higher score on the PDI compared to the controls.

Kerr et al. (1991) investigated the association between psychoactive substance use and specific genres of art. Four groups were created comprising three artist groups (writers $[\mathrm{n}=22]$, musicians $[\mathrm{n}=12]$ and painters $[\mathrm{n}=27])$ and a control group $(\mathrm{n}=25)$. No significant 
differences related to the art genres were found. Only musicians used significantly more cannabis and cocaine compared with the other three groups. No difference in the use of narcotics, psychedelics, and tranquilizers were found in any of the other groups.

A study by Fink et al. (2012) examined the differences in creativity, personality traits, latent inhibition and psychopathology in four participant groups. More specifically, actors $(n=17)$ were compared with two clinical populations of alcohol $(n=13)$ and polydrug dependent individuals $(\mathrm{n}=18)$ and a control group of university students $(\mathrm{n}=21)$. The polydrug dependent group and the actors showed higher originality regarding creativity and possessed decreased latent inhibition compared with the other two groups.

Steffenhagen et al. (1966) reported data on 100 male non-clinical substance users compared to 100 male non-users (although the type of psychoactive substances used was not reported). The authors were interested in how useful the Masculinity-Femininity (MF) scale of the Minnesota Multiphasic Personality Inventory would be for measuring creativity and psychoactive substance use. A strong correlation was found between creativity tests and the MF scale. They also reported that drug users scored higher on both tests than non-users.

\section{Results of the case studies}

As with the empirical studies reported above, three groups were again identified in relation to type of psychoactive substances used by the individuals in the five case studies. Psychedelics were the focus of three studies, and in two case studies, the effects of various psychoactive substances were examined.

\section{Psychedelic substances}

Richards and Berendes (1977) reported the case of a depressed female writer that was unable to work and underwent LSD-assisted psychotherapy. After three months of 
psychotherapy, her emotional blocks were said to be resolved and she was able to write again. Jones (2007) presented the case of the cartoon illustrator, Robert Crumb. His works prior to, under the influence, and at the termination of LSD ingestion were content analyzed. Jones' analysis showed that Crumb's psychedelic drug use significantly changed the stylistic approach of his work not only while he was using LSD, but also for a long time after. In a study by Landon and Fischer (1970), psilocybin was administered to two comparative linguists, whose writings were compared to Walt Whitman (the US poet and essayist). Their texts were analyzed on a semantic, syntactic, and rhetoric level. The authors analyzed the differences in word use under the influence of psilocybin. They reported that the more altered the state of consciousness was, the more concrete the semantic orientation was (i.e., syntactical units became shorter and simpler, and the rhetorical structure was modified).

\section{Various substances}

Musicians were the focus of two case studies. Belli (2009) wrote a psychobiographical report about Brian Wilson (of US group The Beach Boys). The relationship between his mental disorder and creativity and the effects of substance use on his creativity were studied. Wilson used various substances (tobacco, alcohol, amphetamines, and LSD). Cannabis and LSD were unambiguously reported to influence Wilson's creativity. He smoked cannabis because of its auditory alteration. LSD changed his perception, having an indirect effect to his creative work. Cocaine and amphetamines were reported to have helped him against depressive symptoms, but these substances were reported as not being influential to his creativity.

Holm-Hadulla (2013) examined the drug use of Jim Morrison (lead singer of US group The Doors) and related it to his creativity. Morrison suffered from alcoholism 
throughout his adult life and abused many different psychoactive substances (tobacco, cannabis, LSD, mescaline, cocaine and heroin). It was reported that the psychoactive substances were used for pleasure and coping stress but not to enhance creativity. It was also reported that he was unable to write anything while intoxicated. The heavier alcohol and drug intake hindered his work and relationships.

\section{DISCUSSION}

In this systematic literature review, 14 empirical studies and five case studies were identified examining the relationship between creativity/artistic creative process and psychoactive substance use. The most notable observation was that the findings of these studies show only limited convergence. The main reason for this is likely to be found in the extreme heterogeneity concerning the objectives, methodology, samples, applied measures, and psychoactive substances examined among the small number of studies. Consequently, it is hard to draw a clear conclusion about the effect of psychoactive substance use on creativity based on the reviewed material.

Despite the limited agreement, most of the studies confirm some sort of association between creativity and psychoactive substance use, but the nature of this relationship is not clearly established. The frequently discussed view that the use of psychoactive substances leads to enhanced creativity was by no means confirmed. What the review of relevant studies suggests is that: (i) substance use is more characteristic in those with higher creativity than in other populations (Preti \& Vellante, 2007; Jones et al, 2009), and (ii) it is probable that this association is based on the inter-relationship of these two phenomena. At the same time, it is probable that there is no evidence of a direct contribution of psychoactive substances to enhanced creativity of artists. Rather, substances act indirectly by enhancing experiences and 
sensitivity, and loosening conscious processes that might have an influence on the creative process. Thus, in a sense, the artist will not be more creative but the quality of the artistic product will be altered due to substance use (Dobkin de Rios \& Janiger, 2003). This is also suggested by the study of Landon and Fischer (1970). On the other hand, it appears that psychoactive substances may have another role concerning artists, namely that they stabilize and/or compensate a more unstable functioning. This function might also be present in connection with specific mental disorders (Fink et al, 2012; Holm-Hadulla \& Bertolino, 2013)

Beyond the artistic product, it is also observed that (iii) specific functions associated with creativity appear to be modified and enhanced in case of ordinary individuals due to psychoactive substance use. However, it needs to be emphasized that these studies examined specific functions while creativity is a complex process. In light of these studies, it is clear that psychoactive substances might contribute to a change of aesthetic experience (Korngold, 1963), or enhanced creative problem solving (Harman et. al, 1966). Furthermore, Jones' (2007) findings showed that LSD changed a cartoon illustrator's style. Similarly, in Belli's (2009) case study, the modification of musical style was reported connected to substance use. However, these changes in themselves will not result in creative production (although they may contribute to the change of production style or to the modification of certain aspects of pieces of arts). What was also shown is that (iv) in certain cases, substances may strengthen already existing personality traits (Fischer \& Scheib, 1971).

In connection with the findings reviewed, one should not overlook that studies focused on two basically different areas of creative processes. Some studies examined the actual effects of a psychoactive substance or substances in a controlled setting, while others examined the association between creativity and chronic substance users. These two facets 
differ fundamentally. While the former might explain the acute changes in specific functions, the latter may highlight the role of chronic substance use and artistic production.

It should also be noted that the studies reviewed here differ not only regarding their objectives and methodology, but also show great heterogeneity in quality. Basic methodological problems were identified in many of these studies (small sample sizes, unrepresentative samples, reliance on self-report and/or non-standardized assessment methods, speculative research questions, etc.). Furthermore, the total number of empirical studies was very few $(\mathrm{N}=14)$. At the same time, the topic is highly relevant both in order to understand the high level of substance use in artists and in order to clarify the validity of the association present in public opinion. However, it is important that future studies put specific emphasis on adequate methodology and clear research questions.

\section{REFERENCES}

Allport, G. W., Vernon, P. E. \& Lindzey, G. (1931). Study of Values. Boston: Houghton Mifflin.

Barron, F. \& \& Welsh, G. S. (1987). Barron-Welsh Art Scale. Menlo Park, California: Mind Garden Inc.

Belli, S. (2009). A psychobiographic alanalysis of Brian Douglas Wilson: Creativity, drugs, and models of schizophrenic and affective disorders. Personality and Individual Differences, 46, 809-819.

Christensen, P. R., Memfield, P. R. \& Guilford, J. P (1958). Consequences. Beverly Hills, CA: Sheridan. 
Cochrane Non-Randomised Studies Methods Group (2008). Draft chapters for the Guidelines on Non-randomised studies in Cochrane reviews. Retrieved July 16, 2008, from http://www.cochrane.dk/nrsmg/guidelines

Cooper, H. (2003). Editorial. Psychological Bulletin, 129, 3-9.

Dobkin de Rios, M. \& Janiger, O. (2003). LSD, spirituality, and the creative process. Rochester, VT: Park Street Press.

Edwards, J. (1993). Creative abilities of adolescent substance abusers. Journal of Group Psychotherapy, Psychodrama \& Sociometry, 46, 52-60.

Ehrenzweig, A. (1970). The hidden order of art. London: Paladin.

Fink, A., Slamar-Halbedl, M., Unterrainer, H. F. \& Weiss, E. M. (2012). Creativity: Genius, madness, or a combination of both? Psychology of Aesthetics, Creativity, and the Arts, 6(1), 11-18.

Fischer, R. \& Scheib, J. (1971). Creative performance and the hallucinogenic druginduced creative experience or one man's brain-damage is another's creativity. Confinia Psychiatrica. 14, 174-202.

Fischer, R., Fox, R. \& Ralstin, M. (1972). Creative Performance and the Hallucinogenic Drug-Induced Creative Experience. Journal of Psychedelic Drugs, 5(1), 29-36.

Forgeard, M. J. C. \& Elstein, J. G. (2014). Advancing the clinical science of creativity. Frontiers in Psychology, 5, 613.

Frecska, E., Móré Cs. E., Vargha, A. \& Luna, L. E. (2012). Enhancement of creative expression and entoptic phenomena as after-effects of repeated ayahuasca ceremonies. Journal of Psychoactive Drugs, 44, 191-199

Gough, H.G. 1979. A creative personality scale for the adjective check list. Joumal of Personality and Social Psychology, 39, 1398-1405. 
Harman, W. W., McKim, R. H., Mogar, R. E., Fadiman, J. \& Stolaroff, M. J. (1966). Psychedelic agents in creative problem-solving: a pilot study. Psychological Reports. $19,211-227$

Holm-Hadulla, R. M. \& Bertolino, A. (2014). Creativity, Alcohol and Drug Abuse: The Pop Icon Jim Morrison. Psychopathology, 47,167-73

Iszáj, F. \& Demetrovics, Z. (2011). Balancing between sensitization and repression: The role of opium in the life and art of Edgar Allan Poe and Samuel Taylor Coleridge. Substance Use and Misuse, 46, 1613-1618

Jäger, A. O., Süß, H.-M. \& Beauducel, A. (1997). Berliner Intelligenzstruktur-Test. Göttingen: Hogrefe

Jones, M. T. (2007). The creativity of crumb: Research on the effects of psychedelic drugs on the comic art of Robert Crumb. Journal of Psychoactive Drugs, 39, 283-291.

Jones, K. A., Blagrove, M. \& Parrott, A. C. (2009). Cannabis and ecstasy/ MDMA: Empirical measures of creativity in recreational users. Journal of Psychoactive Drugs. 41(4), 323-329

Jung, C.G. (1971). Über das phänomen des geistes in kunst und wissenschaft. Olten, Switzerland: Walter-Verlag AG.

Kerr, B. \& Shaffer, J. \& Chambers, C., \& Hallowell, K. (1991). Substance use of creatively talented adults. Journal of Creative Behavior, 25(2), 145-153.

Khantzian, E. J. (2003) .Understanding addictive vulnerability: An evolving psychodynamic perspective. Neuropsychoanalysis, 5(1,), 5-21

Knafo, D. (2008). The senses grow skilled in their craving: Thoughts on creativity and addiction. Psychoanalytic Review, 95, 571-595.

Korngold, M. (1963). LSD and the creative experience. Psychoanalytic Review. 50, 682-85 
Kris, E. (1939). On inspiration. Preliminary notes on emotional conditions in creative states. International Journal of Psychoanalysis, 20, 377-389.

Kris, E. (1962). Psychoanalytic Explorations in Art. New York: International Universities Press.

Landon, M. \& Fischer, R. (1970). On similar linguistic structures in creative performance and psilocybin-induced experience. Confinia Psychiatrica, 13, 115-38

Lawshe, C. H. \& Harris, D. H. (1960). Purdue Creativity Test. W. Lafayette, Ind.: Purdue Research Found.

Lowe, G. (1995). Judgements of substance use and creativity in 'ordinary' people's everyday lifestyles. Psychological Reports. 76, 1147-1154

Maslow. A. H. (2011). Toward a psychology of being. Mansfield Centre, CT: Martino Publishing.

Mednick, S. A. \& Mednick, M. T. (1967). Examiner's manual, Remote Associates Test. Boston, MA: Houghton Mifflin.

Miller, D. R. (1955). Subject of Object Visualization. Monterey, CAL: California Test Bureau.

Oleynick, V. C., Thrash, T. M., LeFew, M. C., Moldovan, E. G. \& Kieffaber, P. D. (2014). The scientific study of inspiration in the creative process: challenges and opportunities. Frontiers in Human Neuroscience, 8, 436.

Peters, E. R., Joseph, S. A. \& Garety, P. A. (1999). The measurement of delusional ideation in the normal population: Introducing the PDI (Peters et al. Delusions Inventory). Schizophrenia Bulletin, 25, 553-576.

Plucker, J. A., McNeely, A. \& Morgan, C. (2009). Controlled substance-related beliefs and use: Relationships to undergraduates' creative personality traits. Journal of Creative Behavior, 43(2), 94-101 
Preti, A. \& Vellante, M. (2007). Creativity and psychopathology. Higher rates of psychosis proneness and nonright-handedness among creative artists compared to same age and gender peers. Journal of Nervous and Mental Disease, 195(10), 837-845

Richards, W. A. \& Berendes, M. (1977-78). LSD-assisted psychotherapy and dynamics of creativity: A case report. Journal of Altered States of Consciousness, 3(2), 131-146

Rogers, C. R. (1961). On becoming a person. Boston: Houghton Mifflin Company.

Schafer, G. \& Feilding, A. \& Morgan, C. J. A. \& Agathangelou, M. \& Freeman, T. P. \& Curran, H. V. (2012). Investigating the interaction between schizotypy, divergent thinking and cannabis use. Consciousness and Cognition, 21, 292-298

Scheier, M. F. \& Carver, C. S. (1985). Optimism, coping, and health: Assessment and implications of generalized outcome expectancies. Health Psychology, 4, 219-247

Steffenhagen, R. A., McCann, H. Gilman \& McAree, C. P. (1976). Personality and drug use: A study of the usefulness of the Mf Scale of the MMPI in measuring creativity and drug use. Journal of Alcohol and Drug Education, 21(3), 8-16.

Stroup, D. F., Berlin, J. A., Morton, S. C., Olkin, I., Williamson, G. D., Rennie, D., et al. (2000). Meta-analysis of observational studies in epidemiology: A proposal for reporting. Journal of the American Medical Association, 283, 2008-2012.

Torrance, E. P. (1974). Torrance Tests of Creative Thinking. Bensenville, Illinois: Scholastic Testing Service, Inc.

Thrash, T. M. \& Elliot, A. J. (2003). Inspiration as a psychological construct. Journal of Personality and Social Psychology, 84, 871-889.

Thrash, T. M., Maruskin, L. A., Cassidy, S. E., Fryer, J. W. \& Ryan, R. M. (2010). Mediating between the muse and the masses: inspiration and the actualization of creative ideas. Journal of Personality and Social Psychology, 98, 469-487 
Witkin, H. A. (1950). Individual differences in ease of perception of embedded figures. Journal of Personality, 19, 1-15 


\begin{tabular}{|c|c|c|c|c|c|c|c|c|}
\hline$\infty$ &. & 9 & $u$ & + & $\omega$ & $N$ & - & \\
\hline 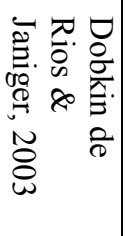 & $\begin{array}{l}5 \\
0 \\
\vdots \\
0 \\
5 \\
0 \\
0\end{array}$ & 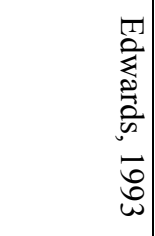 & 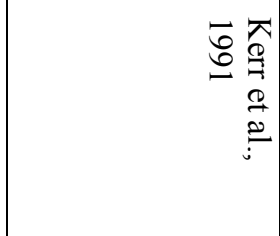 & 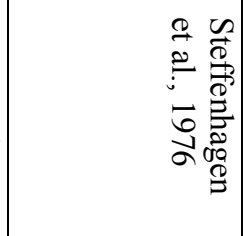 & 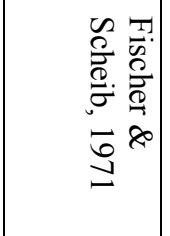 & 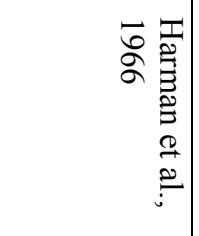 & 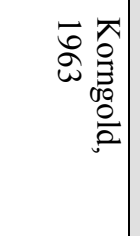 & 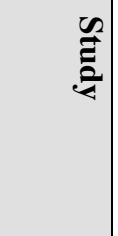 \\
\hline $\begin{array}{l}c \\
w \\
>\end{array}$ & $\subseteq$ & $\begin{array}{l}\text { D } \\
D\end{array}$ & $\begin{array}{l}c \\
\mathbb{N} \\
>\end{array}$ & $\underset{D}{\stackrel{c}{p}}$ & $\begin{array}{l}c \\
D \\
D\end{array}$ & $\begin{array}{c}\stackrel{D}{D} \\
D\end{array}$ & $\begin{array}{l}c \\
\vec{D}\end{array}$ & $\stackrel{2}{\varrho}$ \\
\hline$\sqrt{2}$ & 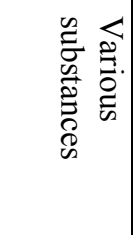 & 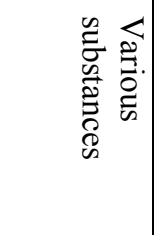 & 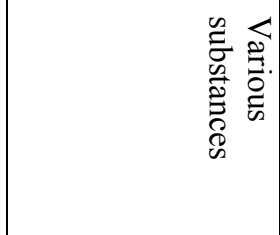 & 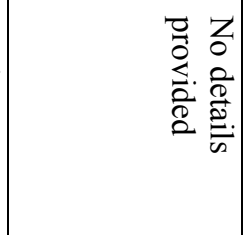 & 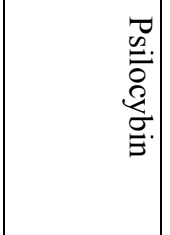 & 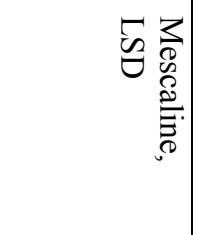 & $\sqrt[5]{0}$ & 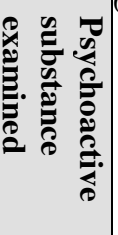 \\
\hline 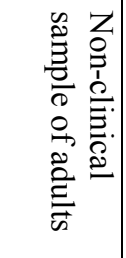 & 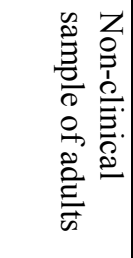 & 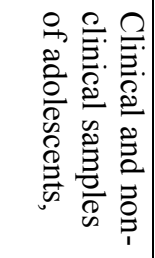 & 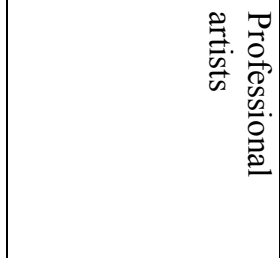 & 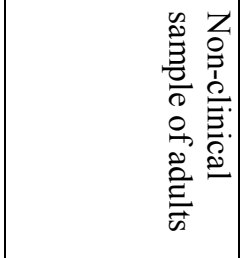 & 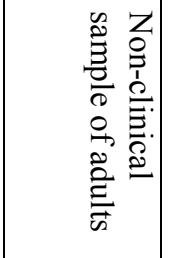 & 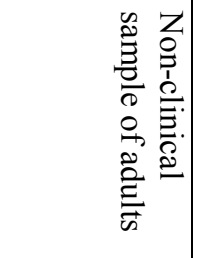 & 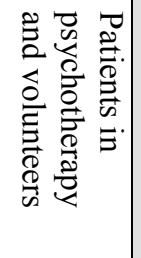 & 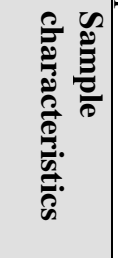 \\
\hline 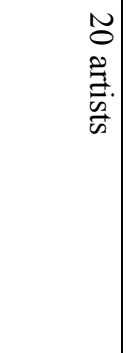 & 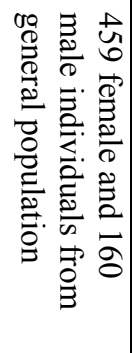 & 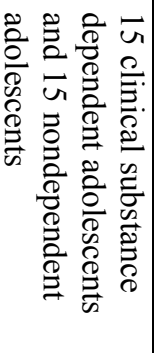 & 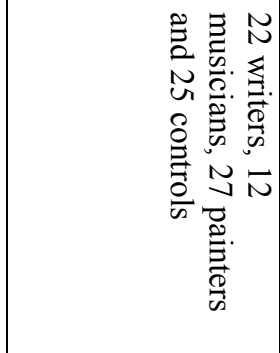 & 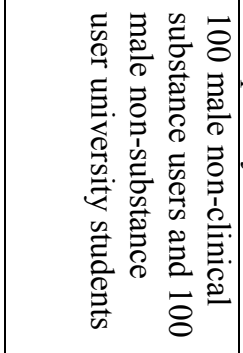 & 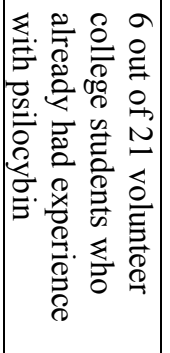 & 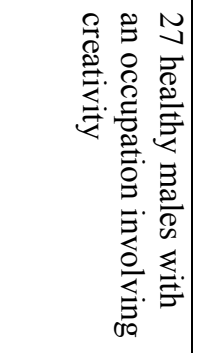 & 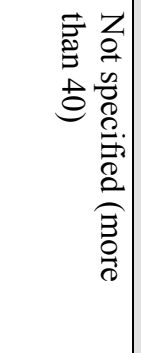 & 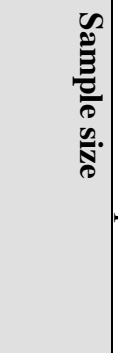 \\
\hline 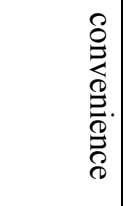 & 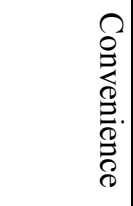 & 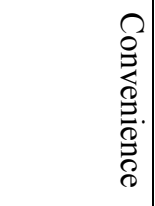 & 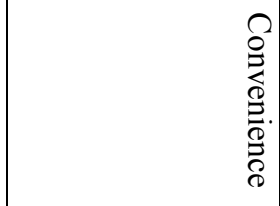 & 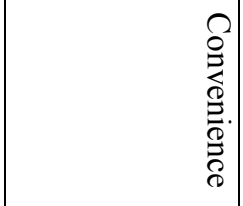 & 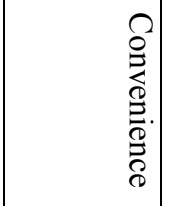 & 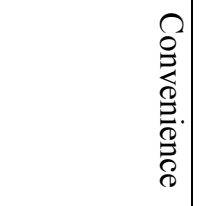 & 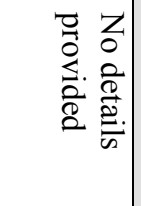 & 音 \\
\hline 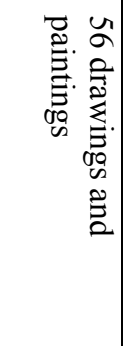 & 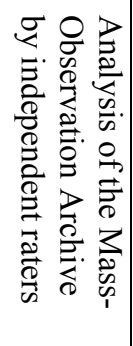 & 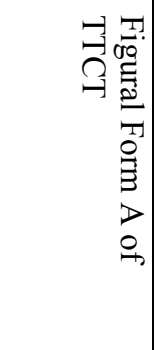 & 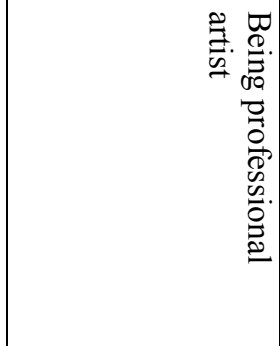 & 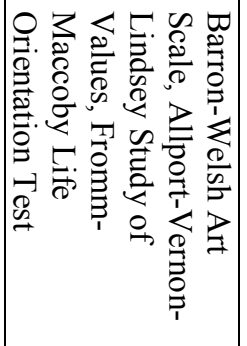 & 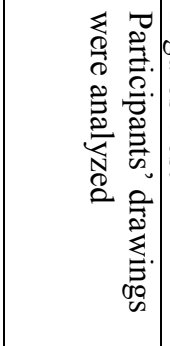 & 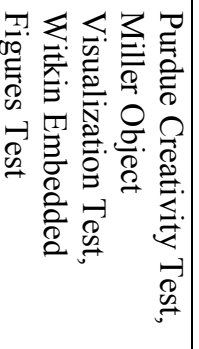 & 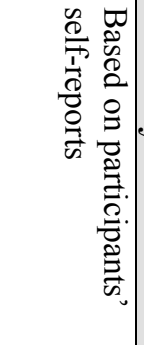 & 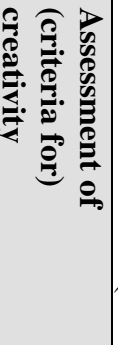 \\
\hline $\begin{array}{l}z \\
0 \\
\vdots \\
0\end{array}$ & 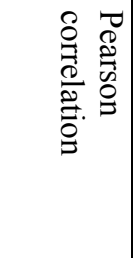 & $\begin{array}{c}\overrightarrow{-} \\
\overrightarrow{\vec{d}} \\
\overrightarrow{0} \\
\overrightarrow{2}\end{array}$ & 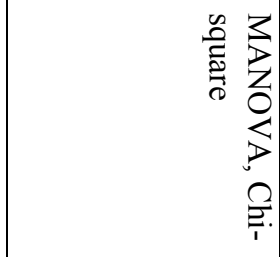 & 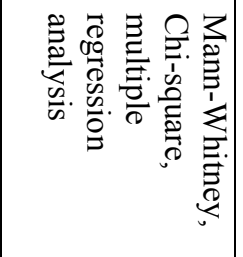 & 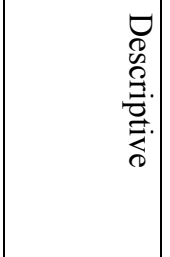 & 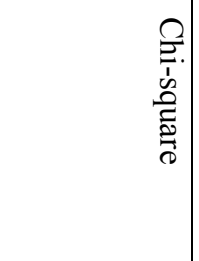 & $\begin{array}{l}z \\
\text { a } \\
\vdots \\
0\end{array}$ & 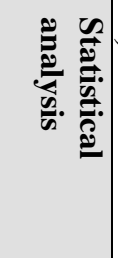 \\
\hline+ & + & & 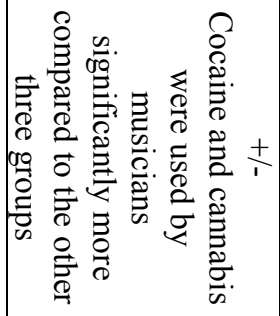 & + & ' & + & + & 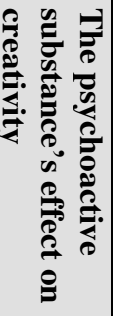 \\
\hline
\end{tabular}




\begin{tabular}{|c|c|c|c|c|c|c|c|c|c|}
\hline$\vec{\partial}$ & $\bar{u}$ & & $\stackrel{\square}{ \pm}$ & $\vec{\omega}$ & $\bar{N}$ & $F$ & .0 & .6 & \\
\hline 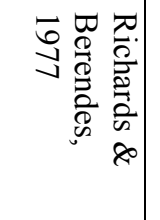 & 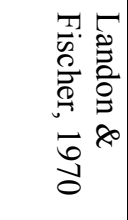 & 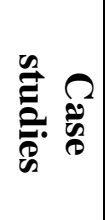 & 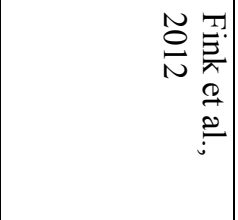 & 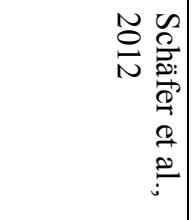 & 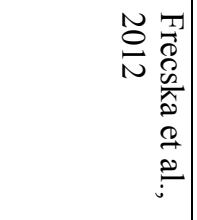 & 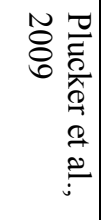 & 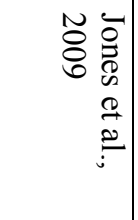 & 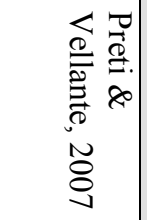 & Ẽ \\
\hline 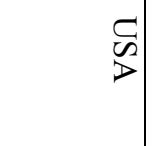 & $\underset{D}{\stackrel{C}{D}}$ & & $\begin{array}{l}\vec{z} \\
\text { a } \\
\text { : } \\
\text {. }\end{array}$ & $\stackrel{\searrow}{\nabla}$ & 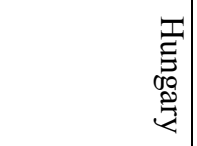 & $\underset{D}{\stackrel{D}{D}}$ & $\begin{array}{l}\underset{m}{d} \\
\frac{w}{\infty}\end{array}$ & $\overrightarrow{\underline{E}}$ & $\stackrel{2}{8}$ \\
\hline $\bar{g}$ & 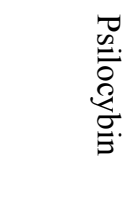 & & 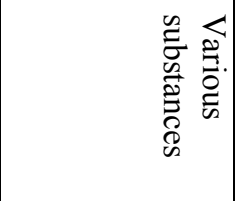 & 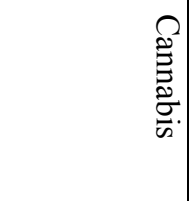 & 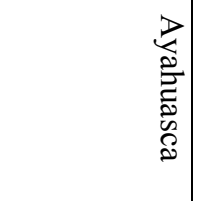 & 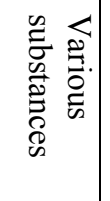 & 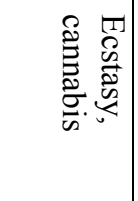 & 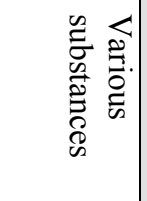 & 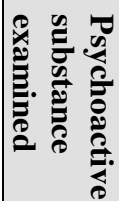 \\
\hline 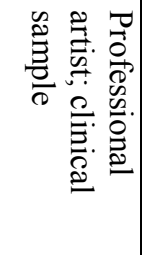 & 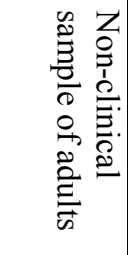 & & 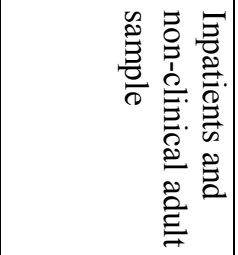 & 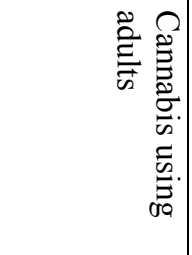 & 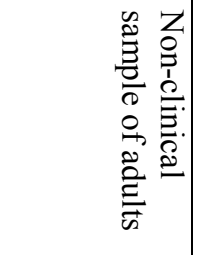 & 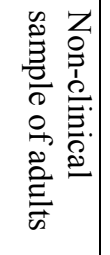 & 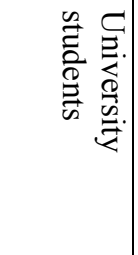 & 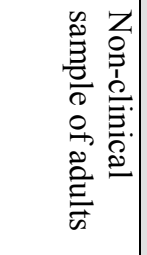 & 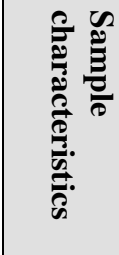 \\
\hline 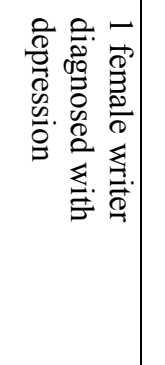 & 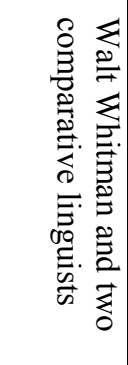 & & 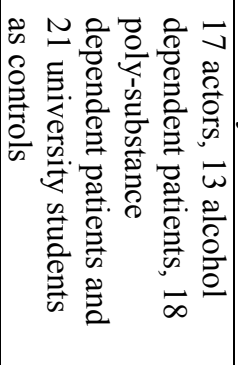 & 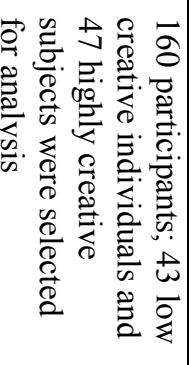 & 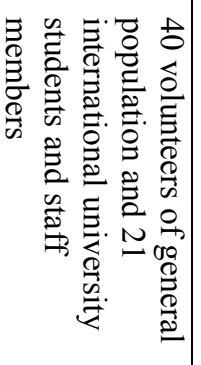 & 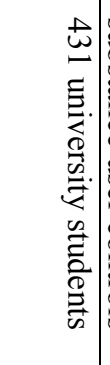 & 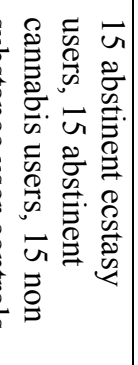 & 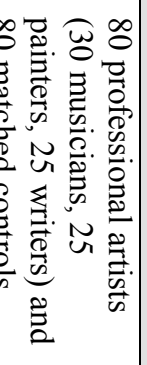 & 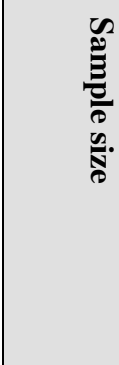 \\
\hline 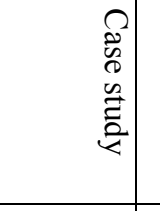 & $\begin{array}{l}\text { के } \\
0 \\
0 \\
0 \\
\tilde{c}\end{array}$ & & 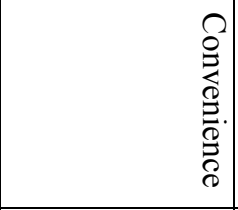 & 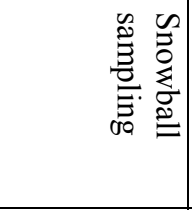 & 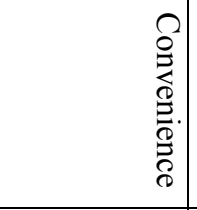 & 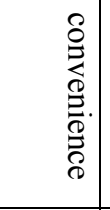 & 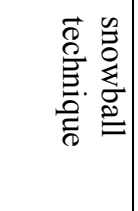 & 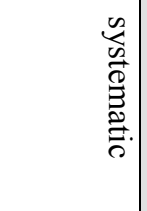 & 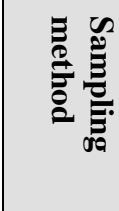 \\
\hline 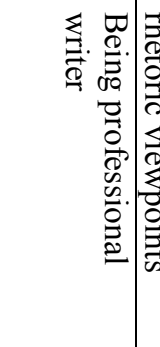 & 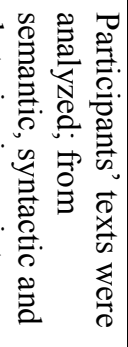 & & 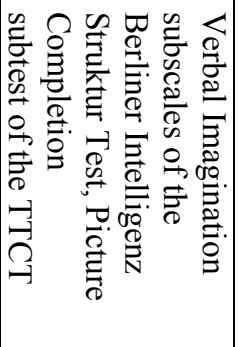 & 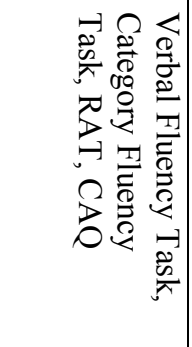 & 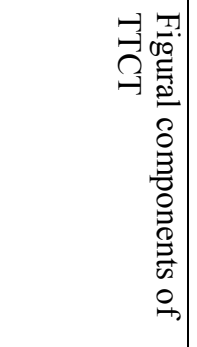 & $\vec{a}$ & 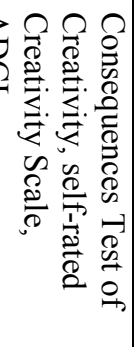 & 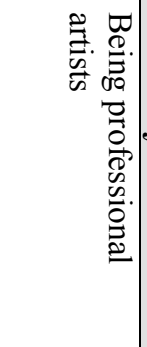 & 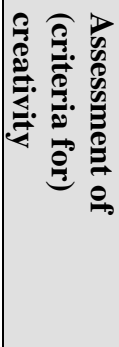 \\
\hline $\begin{array}{l}Z \\
\text { g } \\
\sigma\end{array}$ & $\begin{array}{l}Z \\
0 \\
0\end{array}$ & & 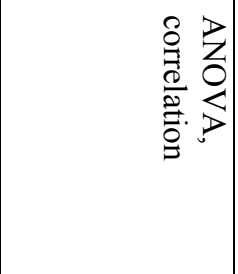 & 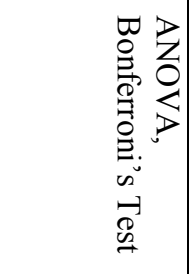 & 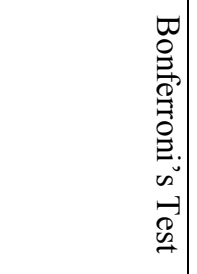 & 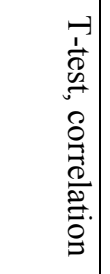 & 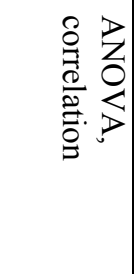 & $\begin{array}{l}z \\
\vdots \\
\vdots\end{array}$ & 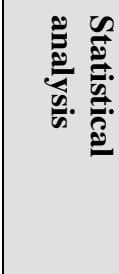 \\
\hline+ & + & & +1 & + & + & ' & 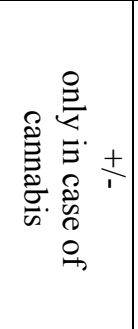 & + & 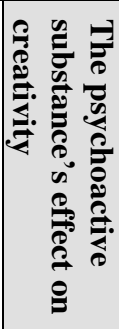 \\
\hline
\end{tabular}




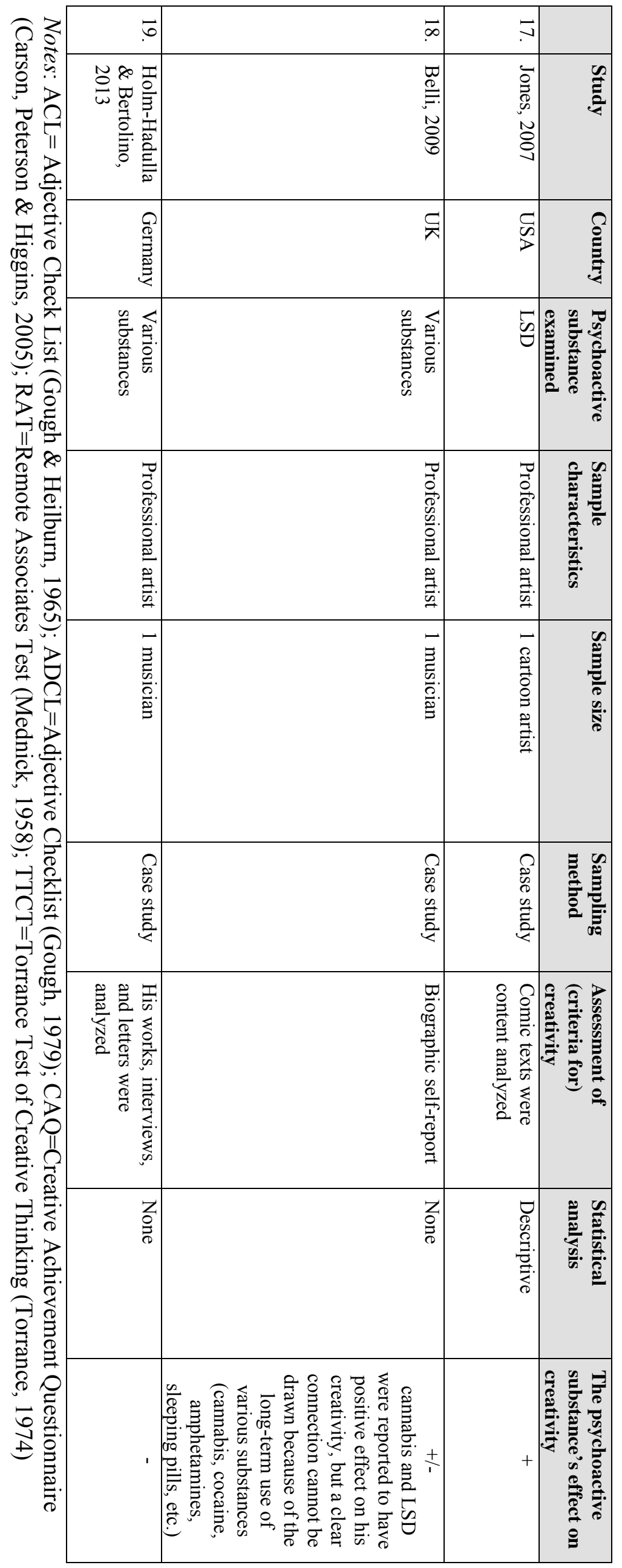

